\title{
Effect of Contrast Hydrotherapy on Pain Intensity And Quality Of Life Outcomes For Patients With Knee Osteoarthritis
}

Manal Ibrahem AbdEIFatah ${ }^{1}$, Soheir Mohammed Weheida ${ }^{2}$, Mimi Mohammed Mekkawy ${ }^{3 .}$

1 Assistant Lecturer Medical Surgical Nursing, Faculty of Nursing, Beni Seuif University, Egypt.

2 Professor of Medical Surgical Nursing, Faculty of Nursing, Alexandria University, Egypt.

3 Professor of Medical Surgical Nursing, Faculty of Nursing, Assuit University, Egypt.

\begin{abstract}
Background: Knee osteoarthritis (OA), also known as degenerative joint disease, is typically the result of wear and tear and progressive loss of articular cartilage. It is most common in elderly women and men. Aim. Evaluate the effect of Contrast Hydrotherapy on Pain Intensity And Quality Of Life Outcomes for Patients With Knee OA .Setting: The study was conducted at Assuit University Hospital in out patients' clinics. Subjects: 90 adult patients with knee osteoarthritis. Tools: were selected three tools Tool I: Bio-socio demographic characteristics Tool II: Numeric pain rating scale. Tool III: WHOQOL questionnaire. Results: Significantly decreased mean scores of pain post contrast hydrotherapy $\mathrm{p}<0.05$ and increased mean scores of all domain of quality of life post one month of contrast hydrotherapy intervention $\mathrm{p}<0.001$. Conclusion: contrast hydrotherapy was significantly effective in reducing pain associated with knee osteoarthritis and improving their quality of life with statistically significance differences . Recommendation: Contrast hydrotherapy should be included in the early effort to manage patients with knee osteoarthritis.
\end{abstract}

\section{Keywords: Knee Osteoarthritis, Contrast Hydrotherapy \& Patient Outcomes.}

\section{Introduction}

Osteoarthritis ( OA) of the knee, also known as knee OA, affects the health of the knee joint and surrounding structures. Risk factors include age (45 and over), female gender, overweight/ obesity, and prior joint injury. While most people over 50 have some age-related structural changes in their knees, not all have symptoms. In those who do have symptoms, the experience of symptomatic knee OA can be a major cause of disability, resulting in reduced workforce and social participation, and loss of (QOL). (Briggs et al., 2016)

Improving population health through public education and preventive health strategies such as reducing obesity rates and sport- or work related injuries; closing evidence-practice gaps in clinicians' practice behaviors; and implementing evidenceinformed models of care to guide health service delivery are important strategies to slow the projected rise of musculoskeletal health conditions facing Australia's health system in the coming years. (Briggs et al., 2014)

In Egypt, more than five million people have OA (Hassan, (2011). Approximately 85\% of individuals over the age of 75 years of age experience some symptoms of OA. $40 \%$ of individuals with the disorder experience significant difficulties with daily activities to the point of interfering with work-related or social roles. According to Hawamdeh \& AlAjlouni (2013). The OA on the knee is common among Arab patients in the late 30s and early 40s with a different clinical pattern and a greater severity in comparison to Western world patients.
Management of OA requires multidisciplinary approach that includes, but not limited to pharmacotherapy, psychology, physical therapy, occupational therapy and surgery. The goals of treatment of patients with OA are to reduce pain and other symptoms and to improve functional capacity. The American College of Rheumatology has recently published recommendations for pharmacological and non-pharmacological therapies in OA of the hand, hip, and knee (Hochberg, et al., 2012).

The main goal of any therapy for patients with knee $\mathrm{OA}$ in most cases is to reduce pain and improve the physical functioning (McAlindon, 2014).

Nurses can help decrease symptoms by implementing nonpharmacological methods and ensuring that patients learn the procedures they can use by themselves (Fernandes et al., 2013, Shin, 2014) The nurse should then evaluate whether these methods provide the desired results. Local hot and cold applications are used to decrease the symptoms in knee OA (Kirazli, 2011) It is reported that hot applications can be implemented for decreasing the pain the individuals feel and to provide flexibility, while cold applications can be used to decrease edema and pain.

Contrast water therapy (CWT) uses both heat and cold to treat pain. A review of studies has suggested that, CWT is better at reducing muscle pain after exercise compared with doing nothing or resting (Bieuzen, et al., 2013) The effects of local heat are well reported, alternating application of hot and cold is known to produce marked stimulation of local circulation. It has been shown that a 30 minute contrast bath produces a $95 \%$ increase in local blood 
flow when the lower extremities alone are immersed. When all four extremities are immersed at the same time, there is a $100 \%$ increase in blood flow in the upper extremities and a $70 \%$ increase in the lower extremities (Pizzorno \& Murray, 2013).

\section{Significance of the study}

Osteoarthritis is the most common disease affecting 5.596869 from the total population in Egypt. OA of knees is a common and progressive condition. It is reported that, $6 \%$ of adults suffer from clinically significant knee $\mathrm{OA}$ with the prevalence increasing with each decade of life (National institute of arthritis \& musculoskeletal \& skin diseases, 2016). It has been observed that there was about $60 \%$ patients visited orthopedic outpatient clinics, orthopedic department and physiotherapy with knee $\mathrm{OA}$ at Assuit university hospital according to Assuit hospital statistical records complaining from joint pain, swelling and unable to perform activities of daily living, contrast hydrotherapy may help in reliving patients' pain, It also provide patients with easily functional abilities. Hence this study may be performed to provide evidence for nursing practice.

\section{Aim of the study}

Evaluate the effect of contrast hydrotherapy on pain intensity and quality of life outcomes for patients with knee osteoarthritis.

\section{Research hypothesis}

H1: Applying contrast hydrotherapy to patients with knee osteoarthritis will decrease mean pain scores level than pre the intervention.

H 2: Applying contrast hydrotherapy to patients with knee osteoarthritis will increasing mean quality of life scores than pre the intervention.

\section{Operational definition}

Contrast hydro therapy: it is the application of heating pads, cold packs, or soaked towels three to six alternations between heating and cooling, heating pads for 1-2 minutes \& Cold application for 20 minutes twice daily for one month.

\section{Patient outcomes}

Patient outcomes means measuring pain level and quality of life among patients with knee osteoarthritis.

\section{Patients \& Methods \\ Research design}

Pre \& post experimental research design was utilized to conduct data of this study.

\section{Setting:}

The study was conduct at Assuit University Hospital in out patients' orthopedic clinics.

\section{Subjects:}

Nighty patients were selected and assigned to applied contrast hydrotherapy.

\section{Inclusion criteria:}

- Adult patients, mild or moderate degree of osteoarthritis, no history of previous knee arthroplasty, no orthopedic surgical procedure on the affected knee, no associated diseased such as diabetes mellitus or cardiac diseases, not on pain control medications, not on any kind of metal implants and/ or pacemaker, and no history of receiving corticosteroid injection to the knee within the past 6 months.

\section{Tools of study}

Three tools were used in this study for data collection:

Tool I: demographic characteristics:

It was developed by the researcher based on reviewing related literatures in Arabic. It included the following two parts:

Part (1): Personal data; this part was developed by the resercher to assess patient' age, sex, marital status, level of education.

Part (2): Medical data; was developed by the researcher to assess patient' family history of OA, stages and duration of OA?

Tool II: Numeric Pain Rating Scale: It was developed by McCaffery and Beebe (1993) to assess pain intensity.

Scoring system: The scale consists of $10 \mathrm{~cm}$ line that was numerated from zero to ten in which: $0=$ no pain, 1-3 = mild pain (little interfering with activities of daily living), 4-6 = moderate pain (interfering significantly with activities of daily living), and 7-10 $=$ sever pain (disabling, unable to perform activities of daily living).

Tool III: Quality of life questionnaire WHOQOLBREF, (1997): This tool was developed by WHO. It consists of 26 items of satisfaction that were divided into five domains: Domain 1: quality of life (2 items); Domain 2: Physical health (7 items); Domain 3: Psychological health (6 items); Domain 4: Social relationships (3 items); and Domain 5: environmental health (8 items).

Scoring system: Each item of the WHOQOL-BREF is scored from 1 to 5 on a response scale, which is stipulated as a five point ordinal scale. The scores are then transformed linearly to a 0-100-scale. These two questions include five point response categories for QOL : "very poor", "poor", "neither poor nor good", "good" and "very good" and for Satisfaction with Health: "very dissatisfied", "dissatisfied", "neither satisfied nor dissatisfied", "satisfied" and "very satisfied". Analysis was performed after collapsing the bottom two categories (i.e., for qol "very poor" and "poor"; for Satisfaction with Health "very dissatisfied" and "dissatisfied") and comparing them to the top three. This approach produced the following derived variables: "poor QOL" vs. "good 
QOL" and "dissatisfied with own health" vs. "satisfied with own health". Therefore, unlike the 4 domains, these two questions are treated as binary outcomes.

\section{Validity and Reliability}

Content validity was ascertained by a group of (5) experted from medical surgical nursing at faculty of nursing. Their opinions were elicited regarding the tools format layout, and scoring system. The content of the tool tested regarding the knowledge accuracy, relevant and competency as for reliability the tools were confirmed for consistency by

Cronbach's alpha test . Coeffeciency( alpha $=.871$; $.890 \& 0.921$ ) respectively

\section{Administrative approval:}

An official letter was obtained from the dean of faculty of nursing, Assuit University, to the director of orthopedic clinic, explaining the purpose of the study to obtain the permission to conduct the study.

\section{Ethical consideration:}

- The researcher explained to patients the aim of the research study.

- Patients advised to their rights to withdraw from the study at any points.

- Patients consent was obtained.

- Patients respect, privacy was asserted and information confidentiality was protected using a numbered coded on all questionnaire

\section{Pilot study}

A pilot study was carried out after the development of the tools and before starting the actual data collection, on 4 subjects (5\% of the total sample). The aim of the pilot study was to test the feasibility of the study and the sequence of items. It also served to estimate the time required for filling the questionnaire sheets and applied the intervention which was about 30 - 40 minutes. They were excluded from the total number of the study subjects. The process of pilot study took one week (from 18/2 to 25/2) in August 2017.

\section{Methods}

\section{Procedure}

Sampling and data collection were started and completed during the period from March 2017 to December 2017. The purpose of the study was simply, explained to the patients to obtain their cooperation for data collection and conduct the current study, anonymicy, confidentiality of patients were assured, it was conducted through the following phases:

\section{A. Preparatory phase}

Data collection was done by the researcher at orthopedic clinic using the pre constructed tools as previously mentioned. And how to apply contrast hydrotherapy which alteration between hot \& cold application, hot application for 1-2 min, and cold application for $20 \mathrm{~min}$ twice daily/each day for one month, identified advantages \&adverse effect and complication of contrast hydrotherapy. The researcher was interviewing the patients with knee OA in the orthopedic out patients' clinics to explain purpose and nature of the study and to get their oral consent to participate in the study.

Applied contrast hydrotherapy on 90 patients. The baseline data was collected from patients, using tool I ( personnal \&medical data), which took about 20minutes to be filled out, tool II (pain and its severity) took $10 \mathrm{~min}$ to be filled, tool III( WHO QOL -BREF) which took $30 \mathrm{~min}$ to be filled.

\section{Implementation phase}

Patients were interviewed individually by the researcher in orthopedic out patients clinics and the researcher explained all items of application, then took two sessions for about 30 min for first session, the first session started by explaining the purpose and nature of study and the objectives of the session included; definition of knee OA, causes of knee OA, how to apply contrast hydrotherapy, identified advantages \&adverse effect and complication of contrast hydrotherapy.

The second session included contrast hydrotherapy application by alteration between heating and cooling water by wrapping heated pads for $1-2$ min then cold pads for 20 minutes over the affected OA knee two times/day (in the morning and afternoon) under the researcher observation for 3 observations to ensure that the patients applied the procedure by the correct way The researcher visited orthopedics clinic 3 days/weeks to collect patients data, and after discharge, the researcher contacts each patient in the study by telephone to be sure that they were following the instructions and to encourage them to apply contrast hydrotherapy twice daily for one month, then asked the patients for any complications and how to manage. Each patient in the study group obtained a copy of the teaching booklet.

\section{B. Evaluation phase}

Regarding follow up of patients, patients was evaluated after one month of application of contrast hydrotherapy in the orthopedic outpatient' clinic by using the same previously mentioned tools (Tool II, Tool III). The researcher contacted the patients by direct interview after one month to perform the evaluation to patients.

\section{Statistical Design}

Statistical analysis was done by using Statistical Package for the Social Science (SPSS 20.0). Quality control was done at the stages of coding and data entry. Data were presented by using descriptive statistics in the form of frequencies and percentage for qualitative variables. Chi square was used to test the 
association between two qualitative variables or to detect differences between two or more proportions and the sample size large. Fisher's exact test used to test the association between two qualitative variables or to detect differences between two or more proportions and the sample size is small. Inferential statistical tests of significance such as independent t-test were used to identify group differences and the relations among the study variables and statistical significance was considered at $p \leq 0.05$.

\section{Results}

Table (1): Frequency distribution of patients demographic characteristics pre intervention $(\mathbf{n}=90)$.

\begin{tabular}{|c|c|c|}
\hline \multicolumn{1}{|c|}{ demographic data } & No. & $\%$ \\
\hline Age (years) & & 13.3 \\
\hline $20->30$ & 12 & 26.7 \\
\hline $30->40$ & 24 & 60.0 \\
\hline $41-65$ & 54 & 45.6 \\
\hline Male & & 54.4 \\
\hline Female & 41 & 12.2 \\
\hline Single & 49 & 82.2 \\
\hline Married & & 5.6 \\
\hline Widow & 11 & 67.8 \\
\hline Rarital status & 74 & 32.2 \\
\hline Urban & 5 & \\
\hline Residence & 61 & 58.9 \\
\hline Read and write & 29 & 14.4 \\
\hline Preparatory education & & .0 \\
\hline University & 53 & 16.7 \\
\hline
\end{tabular}

Table (2): Frequency distribution of patients of contrast hydrotherapy with relation to medical data $(n=90)$.

\begin{tabular}{|c|c|c|}
\hline Medical data & No. & $\%$ \\
\hline Family history for osteoarthritis & & \\
\hline Yes & 67 & 74.4 \\
\hline No & 23 & 25.6 \\
\hline Duration (Years) & & 76.7 \\
\hline $1->5$ & 69 & 17.8 \\
\hline $5->10$ & 16 & 3.3 \\
\hline $10->15$ & 3 & 2.2 \\
\hline $15-20$ & 2 & \\
\hline Sean $\mathbf{S D}$ & $4.3 \pm 4.6$ years \\
\hline Stages of knee osteoarthritis & & 5.6 \\
\hline Stage 1 & 5 & 14.4 \\
\hline Stage 2 & 13 & 45.6 \\
\hline Stage 3 & 41 & 34.4 \\
\hline Stage 4 & 31 & 11.1 \\
\hline Ober weight & 10 & 25.6 \\
\hline
\end{tabular}


Table (3): Frequency of pain intensity level between patients of contrast hydrotherapy application pre/ post intervention $(\mathbf{n}=90)$

\begin{tabular}{|c|c|c|c|c|c|c|c|}
\hline & \multirow{2}{*}{ Pain rating scale } & \multicolumn{2}{|c|}{ Pre } & \multicolumn{2}{|c|}{ Post } & \multirow{2}{*}{$\mathbf{X}^{2}$} & \multirow{2}{*}{$\mathbf{P}$ - value } \\
\hline & & No. & $\%$ & No. & $\%$ & & \\
\hline - & No pain & 0 & .0 & 19 & 21.1 & \multirow{6}{*}{172.019} & \multirow{6}{*}{$.0002 * *$} \\
\hline & Mild pain & 0 & .0 & 6 & 6.7 & & \\
\hline & Moderate pain & 5 & 5.6 & 61 & 67.8 & & \\
\hline & Severe pain & 18 & 20.0 & 2 & 2.2 & & \\
\hline & Very severe pain & 38 & 42.2 & 2 & 2.2 & & \\
\hline & Worst pain & 29 & 32.2 & 0 & .0 & & \\
\hline & Mean \pm SD & \multicolumn{2}{|c|}{$8.1 \pm 1.6$} & \multicolumn{2}{|c|}{$3.5 \pm 2.1$} & & \\
\hline
\end{tabular}

Fisher'exact test, Pearson chi-square test, Significance level p at 0.05

Table (4): Comparison between mean and standard deviation of subdomain of quality of life among contrast hydrotherapy patients one month post the intervention $(n=90)$

\begin{tabular}{|l|c|c|c|c|}
\hline \multicolumn{1}{|c|}{ Domains } & Pre & Post & t & P-value \\
\hline Overall QOL \& General Health & $6.2 \pm 1.0$ & $7.2 \pm 1.1$ & 3.274 & $.001^{* *}$ \\
\hline Physical domain & $14.2 \pm 2.2$ & $21.3 \pm 5.1$ & 12.044 & $.000^{* *}$ \\
\hline Psychological domain & $15.9 \pm 2.3$ & $20.3 \pm 2.8$ & 11.239 & $.000^{* *}$ \\
\hline Social domain & $9.1 \pm 1.6$ & $11.7 \pm .8$ & 8.917 & $.000^{* *}$ \\
\hline Environmental domain & $18.3 \pm 3.8$ & $22.9 \pm 3.1$ & 7.053 & $.000^{* *}$ \\
\hline Total Qol & $64.0 \pm 8.1$ & $84.1 \pm 10.1$ & 13.166 & $.000^{* *}$ \\
\hline
\end{tabular}

Independent t test, Significance level p at 0.05

Table (5): Mean and standard deviation of total Quality of life among contrast hydrotherapy one month's post intervention in relation to demographic characteristics $(n=90)$.

\begin{tabular}{|c|c|c|c|c|}
\hline demographic characteristics & Pre & Post & $\mathbf{T} / \mathbf{F}$ & $\mathbf{P}$ - value \\
\hline \multicolumn{5}{|l|}{ Age (years) } \\
\hline $18->30$ & $64.5 \pm 4.6$ & $87.0 \pm 7.0$ & \multirow{3}{*}{6.656} & \multirow{3}{*}{$.0001 * *$} \\
\hline $30->40$ & $67.0 \pm 7.3$ & $84.3 \pm 8.8$ & & \\
\hline $40-65$ & $62.6 \pm 8.7$ & $79.8 \pm 10.6$ & & \\
\hline \multicolumn{5}{|l|}{ Gender } \\
\hline Male & $64.5 \pm 9.1$ & $85.0 \pm 7.9$ & \multirow[b]{2}{*}{6.207} & \multirow[b]{2}{*}{$.0002 * *$} \\
\hline Female & $63.7 \pm 7.2$ & $79.4 \pm 10.9$ & & \\
\hline \multicolumn{5}{|l|}{ Marital status } \\
\hline Single & $63.4 \pm 4.1$ & $83.7 \pm 7.1$ & \multirow{3}{*}{5.207} & \multirow{3}{*}{$.0003 * *$} \\
\hline Married & $64.1 \pm 8.3$ & $81.5 \pm 10.5$ & & \\
\hline Widow & $64.0 \pm 12.4$ & $84.6 \pm 8.4$ & & \\
\hline \multicolumn{5}{|l|}{ Residence } \\
\hline Rural & $63.1 \pm 6.9$ & $81.0 \pm 9.3$ & \multirow[t]{2}{*}{7.132} & \multirow[b]{2}{*}{$.0004 * *$} \\
\hline Urban & $65.9 \pm 10.1$ & $84.0 \pm 11.5$ & & \\
\hline \multicolumn{5}{|l|}{ Education level } \\
\hline Illiterate & $62.7 \pm 8.3$ & $78.7 \pm 10.5$ & \multirow{4}{*}{5.853} & \multirow{4}{*}{$.0005 * *$} \\
\hline Read and write & $63.3 \pm 6.4$ & 81.510 .6 & & \\
\hline Secondary education & $67.0 \pm 7.8$ & $83.9 \pm 7.5$ & & \\
\hline University & $67.6 \pm 8.1$ & $85.4 \pm 8.6$ & & \\
\hline
\end{tabular}

Independent t test, Significance level P at 0.05 
Table (1): Showed that $60 \%$ of studied sample their age was ranged between $41-65$ years, $54.4 \%$ were females, $82.2 \%$ married , $67.8 \%$ were living in rural areas, $58.9 \%$ were illiterate among studied group.

Table (2): presented that three quarters (74.4\%) of studied sample had previous family history for OA, the majority and just above three quarters $(76.7 \%)$ of them their disease duration was less than five years ago, two fifth $(45.6 \%)$ suffered from stage three of $\mathrm{OA}$, and more than half of them were obese respectively .

Table (3): Indicated that $35.2 \%$ of them were suffering from worst pain pre applying the intervention compared to no one post intervention with highly statistically significance differences $p-$ value .0002 .

Table (4): It is clear from this table that increasing the mean scores after one month post the intervention regarding all domain of quality of life with statistically significance differences in physical, psychological, social domains and total quality of life where $P$ - value $.013, .005, .0001 \& .05$ respectively.

Table (5): This table presented that there are differences between total quality of life with their age and gender which $p$-value $.02 \& .001$ respectively.

\section{Discussion}

Osteoarthritis , particularly at the knee, is a leading cause of disability in older adults characterized by progressive articular cartilage loss resulting in joint pain and disability (Farr et al., 2013) Some risk factors contribute to the appearance of the disease, such as sex, age, trauma, overuse, and genetic conditions. With disease progression, patients' complaints of physical limitations, pain, and functionality restriction increase, leading to an important decrease in their qol (Kawano et al., 2015).

Regarding the patient age in the current study found that OA increase with age. These findings are similar to that which reported in the literature Ringdahle, (2011) along with the increases in age, there is an exponential increase in the associated risk factor of obesity, due to progressive sedentary behavior, changes in lifestyle patterns, diet routine, and work environment conditions among the adult population. Radiographic damage in a knee also increases with age, even in the absence of disease, demonstrating that mild joint degradation may occur and accumulate with aging.

Regarding patient' sex the result of the present study found that women have increased risk than men of developing knee OA. This agrees with (Koonce \& Bravman, (2013), Im, et al., (2014), Shin, (2014) because a withdrawal from estrogen at menopause may be a trigger, hormonal changes and osteoporosis, which may accelerate degenerative changes in multiple joints, changes in muscle strength, the presence of less muscle mass and more fat mass, load on joints, pelvic structure, knee morphology, neuromuscular strength, hormonal changes occurring with age, and changes in the balance between bone formation and bone reabsorption.

In a recent study in Egypt by Abd Elstaar et al., (2016) assessed the qol in patients with primary knee OA which involved 116 patients admitted to the outpatient clinic of rheumatology and orthopedics in Menoufia University Hospital reported that $74.1 \%$ of these patients were women and $25.9 \%$ were men.

Jørgensen, et al., (2011) found living in a rural setting was related to OA. Also, A Systematic Review and Meta-Analysis were done by Usenbo et al., (2015) and mentioned that highest prevalence of $33.1 \%$ for knee OA in rural South Africa. It is possible that participants who live in rural areas may engage in harder labor e.g., agriculture, which may increase disease risk.

In relation to educational level, more than half of the cold group \& contrast group were illiterate which agreed with Jhun, et al., (2013) \& Alkan, et al., (2014) on the other side patients with higher education had better functional capacity when compared to elementary school-educated patients. Current study concluded that functional limitation was also dependent on the level of education.

Regarding Body Mass Index (BMI) a recent study in Egypt done by Ramadan, et al., (2016) evaluated the impact of physical exercise on the activities of daily living in women with early OA recruited from the outpatient clinic of El-Demerdash University Hospital, and presented that more than half of studied patients were obese.

Regarding to pain this study result indicated that more than one third of them were suffering from worst pain pre applying the intervention compared to no one post intervention with highly statistically significance differences. This result consistent with study was done in Egypt by Shehata \& Fareed (2013) that compared the effect of cold, warm and contrast therapy on controlling knee OA associated problems carried out in orthopedic outpatient clinics of Menoufia University and teaching Hospitals, and concluded that all of the three methods (cold, warm and contrast therapy) of therapy resulted in improvement pain but the most appropriate protocol of treatment to relive pain was contrast therapy.

In a recent study was done in India by Archanah, et al., (2018) investigated the effect of a hydrotherapy based alternate compress on OA of the knee joint, presented that significant results in pre and post cold group and in hydrotherapy group regarding reducing pain sensation. 
Regarding mean scores of quality of life and subdomains the current results found that increasing mean scores post contrast hydrotherapy than pre the intervention regarding all domain of QOL with statistically significance differences. This is similar to recent study was done by Mahmoud, et al., (2018) evaluated health-related quality of life (HR QOL) in primary knee patients using the OA knee hip QOL questionnaire recruited from the Rheumatology and Rehabilitation outpatient clinic, Cairo University and concluded that Egyptian patients with primary knee OA have relatively poor HR QOL. Also, Archanah, et al., (2018) found that there were significant results in pre and post hydrotherapy group about improving QOL in the studied patients.

\section{Conclusion}

Based on the findings of the current study the following conclusion can be highlighted decreased the mean scores of pain intensity post contrast hydrotherapy intervention with highly statistically significance differences. Also, there was increased in the mean scores post contrast hydrotherapy regarding all domain of quality of life with statistically significance differences.

\section{Recommendations}

- Contrast hydrotherapy should be included as an early measure to manage patients with knee osteoarthritis.

- Contrast therapy should be considered as the most effective treatment options for relieving knee symptoms and pain.

- Patients with symptomatic OA of the knee, who are overweight should be encouraged to lose their weight (a minimum of five percent $(5 \%)$ of body weight) and maintain their weight at a lower level.

- Replication of the study on large sample must be considered to allow greater generalization of the results.

\section{References}

1. Abd Elstaara T., Salamab A., Esailyc H., \& Boltyb S., (2016): Quality of life in patients with primary knee osteoarthritis Menoufia Medical Journal, vol (29), Pp. 111-114. Available at http://www.mmj.eg.net.

2. Alkan B., Fidan F., Tosun A., \& Ardıçoğlu O., (2014): Quality of life and self-reported disability in patients with knee osteoarthritis. Med Rheumatol., Vol (24), No. (1), Pp. 166-171.

3. Archanah T., Shashikiran H., Shetty P., \& Chandrakanth K., (2018): Effect of a hydrotherapy based alternate compress on osteoarthritis of the knee joint: a randomized controlled trial. Int J Res Med Sci.;6(4):1444-
1449 www.msjonline.org

4. Bieuzen, F., Bleakley, C., \& Costello, J., (2013): Contrast water therapy and exercise induced muscle damage: A systematic review and metaanalysis. PLOS One vol(4), pp 62356.

5. Briggs A., Cross M., Hoy D., Sanchez-Riera L., Blyth F., \& Woolf A., (2016): Musculoskeletal health conditions represent a global threat to healthy aging: A report for the 2015 World HealthOrganisation World Report on Ageing and Health. Gerontologist.;56(S2):S234-S55.

6. Briggs A., Towler S., Speerin R., \& March L., (2014): Models of care for musculoskeletal health in Australia: now more than ever to drive evidence into health policy and practice. Aust Health Rev. Aug 4;N38Vol(4):pp401-5.

7. Farr J., Miller L., \& Block J., (2013): Quality of life in patients with knee osteoarthritis: a commentary on nonsurgical and surgical treatments. Open Orthop Vol (7), Pp. 619-623.

8. Fernandes, L., Hagen, K., Bijlsma, J., Andreassen, O., Christensen, P., Conaghan, P. G., \& Vliet Vlieland, T., (2013): EULAR recommendations for the non-pharmacological core management of hip and knee osteoarthritis. Annals of the Rheumatic Diseases, Vol (72), Pp. 1125- 1135 .

9. Hassan, B., (2011): Comparative clinical study of non-pharmacologic interventions for relieving moderate to severe knee pain in elderly patients. Unpublished thesis, DSN, Alexandria: University of Alexandria, Faculty of Nursing.

10. Hawamdeh Z., \& Al-Ajlouni J., (2013): The clinical pattern of knee osteoarthritis in Jordan: a hospital based study. Int. J. Med. Sci. Vol (10), No. (6), Pp. 790-795.

11.Hochberg M., Altman R., Toupin April K., Benkhalti M., Guyatt G., \& McGowan J., (2012): American College of Rheumatology 2012 recommendations for the use of nonpharmacologic and pharmacologic therapies in osteoarthritis of the hand, hip, and knee. Arthritis Care Res; vol (64), Pp.465-74.

12. Jhun H., Sung N., \& Kim S., (2013): Knee pain and its severity in elderly Koreans: prevalence, risk factors and impact on quality of life. J Korean Med Sci.;Vol (12), Pp. 1807-1813.

13.Jørgensen K., Pedersen B., \& Nielsen N., (2011): Socio-demographic factors, reproductive history and risk of osteoarthritis in a cohort of 4.6 million Danish women and men. Osteoarthritis Cartilage;vol (19):pp1176-82.

14. Kawano M., Araújo I., Castro M., \& Matos M., (2015): Assessment of quality of life in patients with knee osteoarthritis. Acta Ortop Bras vol 23:pp307-310. 
15. Kirazl,, Y., (2011). Current approach to the guidelines for the diagnosis and treatment of osteoarthritis. Turkish Journal of Geriatrics, $\operatorname{vol}(14)$, pp119- 125.

16. Koonce R., \& Bravman J., (2013): Obesity and osteoarthritis: more than just wear and tear. J Am Acad Orthop Surg; (vol 21), Pp. 161-9.

17.Mahmoud G., Moghazy A., Fathy S., \& Niazy M., (2018): Osteoarthritis knee hip quality of life questionnaire assessment in Egyptian primary knee osteoarthritis patients: Relation to clinical and radiographic parameters. The Egyptian Rheumatologist, https://doi.org/10.1016/j.ejr.2018.05.001 11101164/

18. McAlindon T., (2014): OARSI guidelines for the non-surgical management of knee osteoarthritis, Osteoarthritis Research Society International, vol (22), Pp. 363-388 (Level of evidence: 1A).

19.McCaffery M., \& Beebe A., (1993): Pain: Clinical Manual for Nursing Practice. Baltimore: v.v. Mosby Company.

20. National institute of arthritis \& musculoskeletal and skin diseases, handout on health: Osteoarthritis (2016): available http://www.niams.nih.gov/health_info/osteoarthrit is/.

21.Pizzorno J., \& Murray M., (2013): Text book of natural medicine. $4^{\text {th }}$ edition, Chapter 40: Hydrotherapy, Section 3: Therapeutic Modalities, Elsevier.

22. Ramadana R., Alib J., \& Aboushady R., (2016): Impact of physical exercise on daily living activities among women with early osteoarthritis. Egyptian Nursing Journal,vol (13):pp186-192.

23. Ringdahle, (2011): Treatment of Osteoarthritis, American Family Physician, Vol (11), Pp. 12871292.

24.Shehata A., \& Fareed M., (2013): Effect of cold, warm or contrast therapy on controlling knee osteoarthritis associated problems. Int $\mathbf{J} \mathrm{Med}$ Health Pharm Biomed Eng., Vol (7), Pp. 259-65.

25.Shin D., (2014): Association between metabolic syndrome, radiographic knee osteoarthritis, and intensity of knee pain: results of a national survey. J Clin Endocrinol Metab; Vol (99), Pp. 3177-83.

26. Usenbo A., Kramer V., Young T., \& Musekiwa A., (2015): Prevalence of Arthritis in Africa: A Systematic Review and Meta-Analysis. PLOS ONE | DOI:10.1371/journal.pone.0133858.

27. WHO QOL (1997): Development of the World Health Organization WHOQOL-BREF quality of life assessment. The WHOQOL Group. Psychological Medicine, Vol (28), Pp. 551-58. 